\title{
As Bancas de Especiarias do Mercado Público de Porto Alegre e suas Estratégias ${ }^{1}$
}

\author{
Fabiana Böhm Gramkow, Mestranda PPGA/EA/UFRGS \\ e-mail: fbgramkow@ea.ufrgs.br
}

\author{
Neusa Rolita Cavedon, Dra. PPGA/EA/UFRGS \\ e-mail: nrcavedon@ea.ufrgs.br
}

\section{Introdução}

Centro de Porto Alegre. Durante a semana, as principais artérias que cortam a região central da capital dos gaúchos absorvem um fluxo intenso de pessoas que se deslocam num vai e vem constante. $\mathrm{O}$ ponto de chegada desses transeuntes apressados pode ser uma loja de vestuário, um banco, uma repartição pública ou o Mercado Público. Vindo-se pela Rua da Praia, principal via do centro, descendo a Avenida Borges de Medeiros, logo surge uma ampla construção, em estilo neo-clássico, na cor amarelo ouro. Ladeado pela Prefeitura e pelo terminal de ônibus da Praça Parobé, tendo a frente o histórico Chalé da Praça XV e atrás a Avenida Júlio de Castilhos, mas também o Rio Guaíba. O Mercado Público consiste em um centro de compras que reúne especiarias finas e artigos populares, razão pela qual é freqüentado por todas as camadas da população. $\mathrm{O}$ entorno que circunscreve o Mercado é tido como periculoso, na medida em que reúne marginais (pivetes, batedores de carteira). Desempregados, vendedores ambulantes, artistas de rua, desocupados em geral também circulam pelas proximidades do Mercado. A inexistência de um efetivo policial significativo faz com que muitas pessoas evitem caminhar pela área - exceto em caso de extrema necessidade - em face do medo de serem assaltadas. Todavia, para alguns freqüentadores do Mercado Público, a violência circunscreve-se ao exterior do mesmo; internamente, no imaginário dos usuários, o Mercado apresenta-se como um lugar seguro, onde é possível desfrutar-se de um ambiente aprazível. Nas palavras dos usuários:

"Todo mundo que gosta do Mercado... quem gosta do Mercado, quem conhece o Mercado...vem aqui comprar..., tranqüilamente. Não sente medo, não sente cheiro ruim, não, não...".

"...eu venho aqui pra estudar...Atualmente..., ah, o que eu faço atualmente no Mercado. É, já se foi o tempo que eu tinha tempo pra vir passear, fazer qualquer coisa. Atualmente, só venho aqui, sento aqui no banquinho faço alguma coisa que eu tô sem tempo de ir em casa pra fazer né, pra agilizar a minha vida, mais de qualquer jeito, o ambiente não deixa de ser propício, prazeroso, essas coisas, ao meu ver, não posso falar pelos outros".

O Mercado Público teve importante presença no desenvolvimento de Porto Alegre, primeiramente, como ponto de abastecimento da cidade, que agitava a economia e empregava muitas pessoas, e, posteriormente, como ponto turístico e espaço da cidadania.

\footnotetext{
${ }^{1}$ Esta pesquisa conta com recursos do CNPq/FAPERGS/PROPESq-UFRGS
} 
Em 1844, no Largo do Paraíso, hoje Praça XV, foi construído um prédio para abrigar, de forma organizada, diversos quitandeiros que ali formavam um mercado livre. Este foi o primeiro Mercado de Porto Alegre, porém, teve vida curta. Em 1869, foi inaugurado um novo prédio em área de aterro, às margens do rio Guaíba, que abriga o atual Mercado Público. O prédio foi ocupado pelo comércio em geral e alguns estabelecimentos prestadores de serviço. Em 1912, foi construído o segundo pavimento, para abrigar escritórios comerciais e industriais e repartições públicas, produzindo a tipologia arquitetônica que até hoje se conserva.

A história do Mercado passou por momentos difíceis, tais como a enchente de 1941, os incêndios de 1976 e 1979, e as constantes idéias de demolição. Resistindo a tudo isto foi tombado, em 1979, como Patrimônio Histórico e Cultural do Município.

O Poder Executivo do Município, representado pelo Partido dos Trabalhadores - PT, em 1990, deu início ao projeto de restauração mediante o trabalho de uma equipe multidisciplinar. Buscaram com isto resgatar a qualidade estética e a história do edifício, além da otimização da função de abastecimento e dos espaços de sociabilidade e de cultura. A obra terminou, em 1997, contando também com a colaboração dos comerciantes, que durante toda a reforma mantiveram as Bancas em funcionamento.

Com a reforma, a modernidade que já circundava o Mercado, representada por altos edifícios espelhados, com elevadores e arquitetura moderna, foi para dentro do mesmo, onde foram instaladas escadas rolantes, as Bancas ganharam "layouts" mais arrojados, foram contratados seguranças e equipados com rádio de comunicação e criou-se uma central de informações. Vale destacar que todas essas "modernidades" coexistem em um espaço cuja fachada externa é tradicional e, no imaginário da população portoalegrense, esse continua sendo o centro de abastecimento mais tradicional da cidade.

Tendo por objeto de estudo esse "locus" peculiar da cidade de Porto Alegre, a presente pesquisa tem por objetivo percorrer os corredores do Mercado parando em duas Bancas que vendem especiarias, para nelas investigar, através do método etnográfico, as estratégias administrativas levadas a efeito por seus proprietários.

Como esta pesquisa foi desenvolvida em um ambiente onde a gastronomia e a culinária imperam, nada mais apropriado do que, antes de avançarmos o estudo, degustarmos algumas "receitas teóricas".

\section{"Receitas" de Estratégia}

Motta (1998) faz um histórico acerca da evolução da estratégia na Administração, em termos de nomenclatura e forma de utilização. Ele afirma que o termo estratégia começou a ser utilizado no campo administrativo, na década de 50, com o objetivo de orientar as empresas para uma perspectiva de futuro, através do conhecimento de onde e como aumentar sua atuação e melhorar seu desempenho. Porém, somente na década seguinte, no meio empresarial, o conceito foi agregado ao planejamento, dada a necessidade que as empresas sentiram de melhorar seus processos de planejamento e gerência.

Em meados da década de 70, época de mudanças velozes e de grande magnitude, surgiu o termo gerência estratégica introduzido por Ansoff, como sendo: "... o estabelecimento de 
objetivos e metas para a organização, segundo um conjunto de relações entre a organização e o ambiente e que a capacita a alcançar objetivo, que permaneçam ajustados às demandas ambientais" (apud Motta, 1998, p.88).

$\mathrm{Na}$ década seguinte foi inaugurada a era do planejamento e administração estratégicos, onde o futuro é tratado com certa imprevisibilidade, fruto da alta velocidade das mudanças, escassez, hostilidade e ambiente instável. Dado este contexto era necessário ser inovador e adaptar-se às condições do meio para sobreviver.

Entretanto, sabe-se que estratégia contempla mais do que o planejamento em si, ela na verdade é composta por duas partes: formação, que seria um histórico ao captar características passadas e presentes e formulação que se refere ao futuro, ou seja, decisão do que fazer.

Mintzberg et al. (2000) apresentam o processo de formação da estratégia em dez escolas. As três primeiras são de natureza prescritiva, tratando a estratégia como padrões conscientemente deliberados de equilibrar a organização com seu ambiente e propõem a formulação de estratégia como um processo que engloba o desenho conceitual (Escola do Design), o planejamento formal (Escola do Planejamento) e o posicionamento de mercado, de forma a obter uma vantagem competitiva (Escola do Posicionamento). As seis escolas que seguem apresentam um aspecto mais descritivo, tratando a formação da estratégia como um processo visionário (Escola Empreendedora), como um processo mental (Escola Cognitiva), como resultado de um processo emergente (Escola de Aprendizagem), como resultante de um processo de conflito e de disputa de poder (Escola do Poder), como um processo ideológico (Escola Cultural) e como um processo reativo ao meio em que se encontra (Escola Ambiental). Por último, temos a Escola de Configuração que desdobra o processo de formação conforme o ciclo de vida da organização, abarcando características das demais escolas como um todo integrado.

Com uma abordagem mais recente e complementar sobre o processo de formação da estratégia, Whittington (apud Gimenez et al., 1999) identificou quatro enfoques genéricos: clássico, que apresenta a formação da estratégia como um processo racional de análise deliberada com o objetivo de maximizar lucros; evolucionário, que vê o mercado como uma força que seleciona os mais aptos a sobreviverem e que o lucro é o único objetivo organizacional; processualista, vê que as imperfeições do mercado como algo que não permite estratégias ótimas, somando-se ao fato de que as diferenças individuais de interesses e limitações cognitivas impedem planejamentos únicos, portanto, as coalizões de poder restringem a maximização dos lucros; sistêmico considera a possibilidade de uma análise racional para formular estratégias globais, porém, é guiado por objetivos mais pluralísticos e não somente por maximização dos lucros.

Miles e Snow (1978) elaboraram um ciclo adaptativo, em que as empresas por meio da relação estratégia/estrutura e ambiente diferenciam-se nas respostas que dão a três problemas: $o$ problema empreendedor - definição de um domínio de produto/mercado; o problema de engenharia - escolha de sistemas técnicos; e o problema administrativo - relacionado à estrutura e aos processos organizacionais.

A partir da análise deste ciclo, em que as empresas desenvolvem padrões de comportamento relativamente estáveis na busca de um bom alinhamento com o ambiente, Miles e 
Snow propuseram a existência de quatro tipos de estratégias genéricas: defensiva, prospectiva, analítica e reativa, conforme apresentado no Quadro 1.

Quadro 1 - Categorias estratégicas de Miles e Snow

\begin{tabular}{|c|c|c|}
\hline Categoria estratégica & Descriçãa & Funcionamento da estrutura \\
\hline Estratégia Defensiva & $\begin{array}{l}\text { Uma empresa que segue esta estratégia procura } \\
\text { localizar e manter uma linha de } \\
\text { produtos/serviços relativamente estável. Seu } \\
\text { foco concentra-se em uma gama de } \\
\text { produtos/serviços mais limitada do que seus } \\
\text { concorrentes e tenta proteger seu domínio por } \\
\text { meio da oferta de produtos com melhor } \\
\text { qualidade, serviços superiores ou menores } \\
\text { preços. Não procura estar entre os líderes da } \\
\text { indústria, restringindo-se àquilo que sabe fazer } \\
\text { tão bem ou melhor que qualquer um. }\end{array}$ & $\begin{array}{l}\text { Desenvolve um alto grau de } \\
\text { formalização. Acredita em uma } \\
\text { estrutura de organização } \\
\text { funcional que agrupa } \\
\text { especialistas com habilidades } \\
\text { similares em unidades } \\
\text { separadas que executam sua } \\
\text { própria parte no processo de } \\
\text { produção e distribuição. }\end{array}$ \\
\hline $\begin{array}{l}\text { Estratégia } \\
\text { Prospectora }\end{array}$ & $\begin{array}{l}\text { Um empresa que adota esta estratégia está } \\
\text { continuamente ampliando sua linha de } \\
\text { produtos/serviços. Enfatiza a importância de } \\
\text { oferecer novos produtos/serviços em uma área } \\
\text { de mercado relativamente mais ampla. Valoriza } \\
\text { ser uma das primeiras a oferecer novos } \\
\text { produtos, mesmo que todos os esforços não se } \\
\text { mostrem altamente lucrativos. }\end{array}$ & $\begin{array}{l}\text { Deve estar disposta a alterar } \\
\text { sua estrutura organizacional } \\
\text { para propiciar respostas } \\
\text { rápidas a troca de ambiente. } \\
\text { Os funcionários devem } \\
\text { possuir habilidades gerais e } \\
\text { as funções são largamente } \\
\text { definidas para permitir máxima } \\
\text { autonomia. Possui uma baixa } \\
\text { formalização. }\end{array}$ \\
\hline Estratégia Analítica & $\begin{array}{l}\text { Uma empresa que segue esta estratégia tenta } \\
\text { manter uma linha limitada de produtos/serviços } \\
\text { relativamente estável e ao mesmo tempo tenta } \\
\text { adicionar um ou mais novos produtos/serviços } \\
\text { que foram bem-sucedidos em outras empresas } \\
\text { do setor. Em muitos aspectos é uma posição } \\
\text { intermediária entre as estratégias defensiva e } \\
\text { prospectora. }\end{array}$ & $\begin{array}{lrr}\text { Possui uma estrutura } \\
\text { organizacional híbrida por } \\
\text { acomodar estabilidade } \mathrm{e} \\
\text { mudança. Contém divisões } \\
\text { funcionais compostas por } \\
\text { especialistas com } r \text { alta } \\
\text { formalização e divisões de } \\
\text { produtos compostas por } \\
\text { generalistas com baixa } \\
\text { formalização. }\end{array}$ \\
\hline $\begin{array}{l}\text { Estratégia } \\
\text { Reativa }\end{array}$ & $\begin{array}{l}\text { A empresa que adota este tipo de estratégia } \\
\text { exibe um comportamento mais inconsistente do } \\
\text { que os outros tipos. É uma espécie de não- } \\
\text { estratégia. Não arrisca em novos } \\
\text { produtos/serviços a não ser quando ameaçada } \\
\text { por concorrentes. A abordagem típica é } \\
\text { "esperar para ver" e responder somente quando } \\
\text { forçada por pressões concorrentes para evitar a } \\
\text { perda de clientes importantes e/ou manter } \\
\text { lucratividade. }\end{array}$ & $\begin{array}{l}\text { As empresas com este } \\
\text { enfoque só mudam sua } \\
\text { estrutura caso haja uma } \\
\text { considerável mudança no } \\
\text { ambiente. De modo geral não } \\
\text { buscam o alinhamento entre } \\
\text { estrutura e estratégia e } \\
\text { possuem um desenho } \\
\text { operacional solto. }\end{array}$ \\
\hline
\end{tabular}

Adaptado do quadro desenvolvido por Gimenez et al., 1999. 
Conant et al. (1990) sintetizaram as diferenças dos quatro tipos de estratégia propostos por Miles e Snow através das dimensões dos componentes do ciclo adaptativo, conforme apresentado a seguir no quadro 2 .

Quadro 2 - Dimensões do ciclo adaptativo e características dos tipos estratégicos

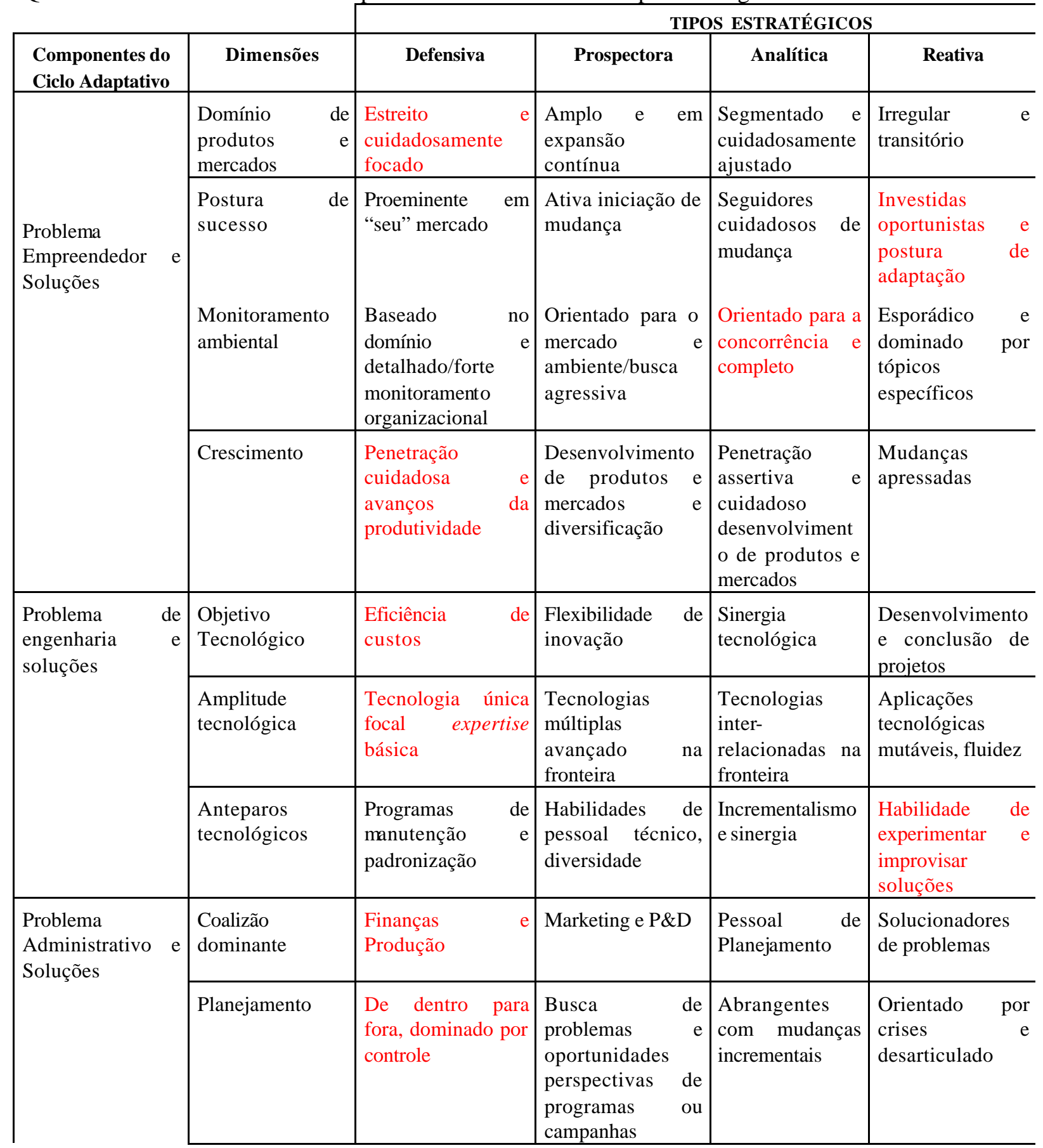




\begin{tabular}{|l|l|l|l|l|l}
\hline Estrutura & $\begin{array}{l}\text { Funcional, } \\
\text { autoridade de linha }\end{array}$ & $\begin{array}{l}\text { Por produtos e ou } \\
\text { mercados } \\
\text { Dominada por } \\
\text { assessores, } \\
\text { orientada por } \\
\text { matriz }\end{array}$ & $\begin{array}{l}\text { Autoridade } \\
\text { formal rígida, } \\
\text { desenho } \\
\text { operacional solto }\end{array}$ \\
\hline Controle & $\begin{array}{l}\text { Centralizado formal } \\
\text { e ancorado em } \\
\text { aspectos } \\
\text { financeiros }\end{array}$ & $\begin{array}{l}\text { Desempenho no } \\
\text { mercado e volume } \\
\text { de vendas }\end{array}$ & $\begin{array}{l}\text { Métodos } \\
\text { múltiplos, } \\
\text { cálculos de } \\
\text { riscos } \\
\text { cuidadosos, } \\
\text { contribuição de } \\
\text { vendas }\end{array}$ & $\begin{array}{l}\text { Evitar problemas } \\
\text { e resolver } \\
\text { problemas } \\
\text { remanescentes }\end{array}$ \\
\hline
\end{tabular}

Fonte: Conant et al., 1990.

\section{Separando os ingredientes para preparar a "receita"}

Nossa primeira visita ao Mercado na condição de pesquisadoras deu-se, no mês de outubro de 2000. Exercitamos a observação participante como consumidoras em um restaurante tradicional e após usufruímos do passeio dirigido oferecido aos estudantes e coordenado pelos funcionários do Memorial do Mercado Público. A escolha das duas Bancas para a realização da pesquisa, ocorreu neste primeiro contato.

A Banca 43 foi a primeira a ser investigada, isto porque, no primeiro dia em que fomos a campo, ela mostrou-se mais acessível por não haver tantos clientes (naquela hora) e, conseqüientemente, mais disponibilidade para conseguirmos informações junto aos permissionários e funcionários.

Cabe ressaltar que as Bancas possuem uma numeração, já há um bom tempo, como forma de organização, sendo que a maioria também adota algum nome, a exemplo da Banca 31, mais conhecida como Banca do Holandês. Com a reforma muitas Bancas mudaram de lugar, porém permanecem com sua numeração original, visto que faz parte da história de cada uma. Segundo o filho do permissionário 2 da Banca 31, ela é a única que permanece no mesmo lugar e com o mesmo espaço físico desde a sua fundação, em 1919.

Este trabalho constitui-se de um relato etnográfico que, conforme descreve Lévi-Strauss, consiste "na observação e na análise dos grupos humanos considerados na sua particularidade ..., e visa a reconstituição, tão fiel quanto possível da vida de cada um deles" (apud Viet, 1967, p. 93).

A pesquisa foi conduzida tendo por técnica, além da observação sistemática e participante, entrevistas com permissionários, funcionários e clientes das Bancas de especiarias realizadas durante dois meses e meio.

As informações fluiram com facilidade, quando menos esperávamos estávamos degustando as especiarias da Banca 43, sendo questionadas sobre a decoração natalina, tendo acesso a fotos inéditas do Mercado Público no início do século.

Apesar da utilização de um roteiro semi-estruturado para as entrevistas, procuramos dar voz aos informantes para que eles falassem livremente.

No diário de campo, além dos relatos das entrevistas, foram registradas as vivências que serviram de base para o amadurecimento das impressões no decorrer do processo de campo.

\footnotetext{
${ }^{2}$ Indivíduo que recebe uma permissão do poder público municipal para administrar uma banca no Mercado.
} 


\section{Elaborando "as receitas" nas Bancas de Especiarias}

\section{Banca 43}

Arlindo Oswaldo Musskopf, em 1949, criou a Banca 43, cujo segmento de atuação corresponde à venda de especiarias. Hoje, a Banca é administrada por três antigos funcionários que trabalharam com o fundador. Neroci, responsável pelo atendimento no balcão, descendente de português, diz que "tem sangue árabe", possui 57 anos, é casado, pai de três filhos, cursou o segundo grau, trabalha - desde os 14 anos - há 42 anos no Mercado Público, mais especificamente na Banca 43. Cláudio Klein, considera-se um guerreiro e apaixonado pelo que faz, para ele não basta trabalhar só pelo dinheiro, é preciso possuir um ideal, construir algo que fique para as próximas gerações, é Presidente da Associação do Comércio do Mercado Público Central de Porto Alegre - ASCOMEPC - também conhecida como Associação dos Permissionários ou Mercadeiros. Oscar Endress, o sócio, a quem cabe executar as compras e os pagamentos. A permissão foi passada para os três funcionários, porque o único filho do primeiro permissionário não quis dar seguimento as atividades do pai, optando por formar-se em Medicina. Assim, coube aos três funcionários, considerados os mais dedicados, levar adiante a tradição da Banca.

Atualmente, a Banca possui dez funcionários: quatro com aproximadamente 20 anos de casa, um com 13 anos, três com quase 10 anos, um com 2 anos e o filho de um dos permissionários que iniciou este ano (dos três filhos do permissionário este foi o único que se interessou por dar seguimento a atividade do pai).

O clima entre funcionários e permisisonários é bastante informal, lembrando uma grande família, uns chamam os outros de "guris", sendo que a maioria possui mais de 45 anos. Reúnemse, eventualmente, nos finais de semana na casa de um dos permissionários para o costumeiro churrasco. Trabalham intensamente e com dedicação, aparentando sempre bom humor e cortesia.

Este "clima de uma família" se dá na relação dos fregueses com os funcionários, não sendo raro, os clientes pagarem lanches; fazerem convites para almoços, para a ingesta de cerveja; ou, ainda, gratificarem os funcionários com gorjetas. Segundo nos revelou o permissionário Neroci:

"(...) de manhã nós vamos tomar café se abre um, dois, três pão diferente, cada um faz seu sanduíche, toma um refrigerante, é que nem uma família. (...) é isso que nós aprendemos com Seu Arlindo, que fazia isto conosco".

"(...) isto aqui é quase como uma família, (...) tem gente aqui que vem quase que todos os dias só para bater um papinho. Tem freguês que diz assim eu gosto tanto do Mercado que preciso vir no Mercado, olhar o Mercado, (...) me distrair um pouco. (...) Isto é bonito".

A Banca apresenta um "layout" onde, de um lado, podemos observar os balcões de frios e, do outro lado, balcões com frutas secas, trufas, marzipans, cucas de mel, etc. No centro entre 
os balcões um corredor que permite a visualização dos mais diferentes produtos nacionais e importados colocados à venda. Os funcionários usam uniforme combinando com o estilo e as cores predominantes nos móveis e na decoração da Banca, ou seja, nos tons bege claro com contornos de marrom. Porém, com o passar do tempo, o tecido dos uniformes começa a ficar velho e desbotado, daí a solicitação dos funcionários para que quando forem providenciados novos uniformes, a tradicional cor verde piscina, que sempre foi a cor dos uniformes da Banca, fosse adotada novamente. Mesmo não combinando muito com o desing e cor da Banca, a idéia foi acatada pelos permissionários.

Dentro da ótica da tradição, tem-se a forma de embalar os produtos. Na Banca 43, as mercadorias são embrulhadas em papel e amarradas com barbante antes de serem colocadas em sacolas plásticas, diferentemente dos supermercados, onde os produtos são acondicionados diretamente em sacolas plásticas.

O perfil dos clientes, apesar de alguns anos para cá ter se tornado mais eclético, ainda é constituído em sua maioria por pessoas de uma faixa etária mais elevada, por volta de 60 e 70 anos, sendo a maioria mulheres e com poder aquisitivo mais elevado (classe média alta). Enfim pessoas, como a Maria Luisa, cliente há bastante tempo: "Se conta o tempo que eu era criança e acompanhava meu pai, deve fazer lá 50 anos".

Contudo, os permissionários buscam ampliar este perfil de consumidor através do uso do e-commerce. Atualmente, participam de um site de compra e venda, também possuem um link dentro do site do Mercado Público. Entretanto, as vendas, via Internet, não estão ocorrendo pois os consumidores parecem não querer abrir mão do contato humano e do atendimento personalizado, que são expressos através do conhecimento que os funcionários possuem acerca de seus gostos, seus nomes, detalhes de suas vidas. Inclusive servindo, muitas vezes, de conselheiros e psicólogos, conforme relatado por Neroci. Além disto, Cláudio nota uma certa resistência no uso deste meio de comunicação, talvez seja em virtude de um certo conservadorismo dos consumidores, principalmente gaúchos, mesmo com bom grau de escolaridade: “... o povo gaúcho é muito conservador nesta parte. (...) não se adequaram a este tipo de trabalho de compra pela Internet."

Possuem uma interessante estratégia de venda. Procuram decifrar hábitos e características dos clientes e com isto oferecem produtos que passam a ser cativos dos mesmos. Por exemplo, quando o cliente é diabético costumam, de posse desta informação, indicar algum produto da linha dietética. Todavia, oferecem apenas um produto, na visão dos permissionários, a oferta de muitos produtos ao mesmo tempo torna-se algo antipático, segundo nos relatou Neroci. Observamos, também, que o pessoal da Banca procura prestar um serviço personalizado ao cliente, a partir das peculiaridades que descobrem acerca do mesmo. Por exemplo, quando identificam ou sabem que um casal não possui filhos, o funcionário sugere que levem uma quantidade menor de produto de modo que possam ter uma rotatividade maior e, por via de consequiência, produtos sempre frescos. Acabam assim criando uma empatia com o freguês que termina por desenvolver uma espécie de fidelidade junto a Banca. Ainda, dentro do espectro da reciprocidade e da fidelidade, encontramos a troca de receitas entre os membros da Banca e os seus fregueses, tanto oralmente como por escrito. O site contempla várias opções de receituários gastronômicos. A página de entrada do site apresenta a seguinte frase: "A mais de meio século dividindo conhecimento com a gastronomia gaúcha". E segue no link "O que é?": "Não é a toa 
que a Banca 43 é considerada não apenas uma banca, mas um Altar, onde seus atendentes não são apenas funcionários, mas sim verdadeiros Sacerdotes da gastronomia. Prove e aprove você também. Pensou em cozinha, pensou Banca 43".

A busca pela proximidade junto ao cliente é evidenciado inclusive no "layout" da banca que procura, apesar do pouco espaço, abrigar o freguês dentro dela. Isto possibilita, aos que atendem na Banca, uma interlocução com o cliente, viabilizando a descoberta de seus gostos, permite fornecer degustação de alimentos, a apresentação de novos produtos, enfim, prestar um "atendimento de acordo", termo usado por Neroci para definir a qualidade dos produtos e serviços da Banca: "(...) nós não gostamos do freguês tá longe de nós, ter esse freguês junto, perto para gente conversar, para bater um papo. (...) perguntando o que quer levar o que não quer. Esse é o nosso lance".

Podemos sentir isto quando durante a primeira incursão na Banca, que se estendeu por quase uma tarde, uma das pesquisadoras foi obsequiada com a degustação de queijo mineiro, presunto defumado, damasco seco e cafezinho. Notamos, através da observação participante, que essa é uma forma de cativar, encantar e reforçar o referencial da Banca em termos de atendimento personalizado. Isto acaba por gerar a eficiente propaganda boca a boca, que para Neroci é o melhor marketing para este tipo de negócio.

É com orgulho que os integrantes da Banca falam de seus clientes ilustres: Presidente Médici, Hebe Camargo, Gaúcho da Fronteira, Kleiton e Kledir. Possuem também estrangeiros na lista de fregueses, tais como funcionários de embaixadas, turistas que experimentam as especiarias e passam a encomendá-las, via fax, recebendo-as por correio (sedex).

$\mathrm{Na}$ área de suprimentos contam com fornecedores nacionais e estrangeiros, possuem fornecedores locais com uma linha artesanal de produtos, como uma família de Pelotas que supre a Banca com doce de pêssego, o favorito da entrevistadora de televisão do eixo Rio-São Paulo, a septuagenária Hebe Camargo.

As Bancas que vendem os mesmos produtos não formam clusters de forma a barganhar e ter ganhos junto aos fornecedores, diminuindo assim o custo e, portanto, podendo ter mais vantagem competitiva que o supermercado, hoje, um dos mais fortes concorrentes do Mercado Público como um todo, na visão de muitos permissionários. Entretanto, Cláudio Klein diz que esta forma de atuação tem que mudar e, como presidente da ASCOMEPC, pretende disponibilizar cursos na área de gestão de negócios para alavancar uma visão mais competitiva em termos de práticas de gestão.

Dentro desta linha podemos observar que Claúdio possui um estilo mais arrojado e com uma visão empresarial mais ampla que a média dos permissionários, mostra-se preocupado em atrair mais clientes através da divulgação do Mercado Público, principalmente, na época de Natal, período em que há maior volume de vendas no comércio. Para tal, em 2000, a ASCOMEPC, juntamente com a Prefeitura de Porto Alegre, promoveu o sorteio de cinco cestas contendo produtos do Mercado para quem fizesse a frase mais criativa relacionando "Mercado Público e Natal". Houve programação de shows, Papai Noel, decoração interna e externa mais evidente que nos anos anteriores e até anúncio em jornal de circulação estadual, contendo a seguinte campanha publicitária: "Mercado Público o bom velhinho - há 131 anos o melhor Natal".

Quanto aos concorrentes dentro do próprio Mercado, constatamos que não são apenas as Bancas que trabalham com especiarias, mas também as que vendem bebidas e produtos 
importados, como é o caso da Banca 26. Entretanto, a principal concorrente da Banca 43 é a Banca 31 (Banca do Holandês).

\section{Banca 31}

A Banca 31 foi fundada em 1919 por Dirk Van Den Brul, um holandês, o que fez com que todos começassem a chamar o estabelecimento de Banca do Holandês, ficando este, posteriormente, sendo o nome oficial da Banca. Tal local é considerado o primeiro ponto de especiarias de Porto Alegre. Quando Dirk faleceu, seus parentes assumiram os negócios, entretanto, não conseguiram manter o desempenho do estabelecimento, passando a permissão para alguns funcionários. Sendo que um destes, Renato Jardim Rosa, hoje, viúvo com 60 anos, atual permissionário, comprou a parte dos demais.

Além da Banca 31, que é gerenciada pelo filho Sérgio, Renato possui outro estabelecimento no Mercado, o Armazém do Confeiteiro, gerenciado pela filha. Segundo Sérgio, nosso informante nesta Banca, há alguns produtos que são comuns a ambos estabelecimentos, sendo assim, fazem apenas uma encomenda que supre as duas Bancas auferindo custo mais baixo.

A Banca possui nove funcionários com idade média de 35 anos, sendo que a maioria tem menos de 10 anos de casa. Segundo Sérgio, funcionários mais jovens possuem menos vícios e manias, também acatam as decisões sem assumir a postura de querer determinar o negócio. $\mathrm{O}$ treinamento é feito de maneira bastante informal, ou seja, o funcionário mais experiente (o que possui mais tempo de serviço) acompanha, ensina e passa conhecimentos para o novato.

A Banca não possui espaço suficiente para abrigar tantos funcionários, contudo o ambiente é bastante descontraído e procuram atender com alegria e cortesia, recebendo inclusive algumas gorjetas. Usam uniformes na cor branca com detalhes na cor laranja, em alusão ao país de origem do primeiro proprietário.

Antes da reforma o perfil dos clientes desta Banca era mais tradicional, pessoas de classe média alta, que compravam há bastante tempo, alguns desde criança, recebendo uma "herança gastronômica" de seus pais. Porém, após a reforma, a clientela se expandiu, visto que mais pessoas começaram a freqüentar o Mercado por este ter se tornado um ambiente mais agradável. Uma das clientes que entrevistamos nesta Banca nos disse que o Mercado antes da reforma não era ambiente para mulheres desacompanhadas, pois eram alvo de muitas cantadas.

Os fregueses assíduos são atendidos pelo nome e têm seus hábitos e gostos reconhecidos pelos funcionários. Por exemplo, a espessura que o presunto deve ser fatiado, a marca do queijo a que estão habituados a consumir são de domínio dos atendentes. Também trocam receitas com o pessoal da Banca, o que lembra o ritual dos colares e pulseiras dos nativos das ilhas Trobriand, estudados por Malinowski (1978), que de tempos em tempos mudavam de lugar e seguiam circulando até retornarem ao mesmo lugar.

$\mathrm{Na}$ Banca 31, igualmente, costumam fazer referência a clientes famosos, como é o caso de Roberto Marinho, que encomenda os figos cristalizados de Caxias do Sul (cidade da serra gaúcha), através de uma senhora carioca que, esporadicamente, compra produtos da Banca.

Além das especiarias, o destaque fica por conta do atendimento. A Banca parece estar passando por uma fase de transição, o filho está assumindo mais a rotina, ficando no caixa, e o permissionário está envolvido com o gerenciamento global das duas Bancas. Sérgio disse que não 
conhece o nome dos clientes mais tradicionais tal como o seu pai e alguns funcionários. Observamos que ele possui um tratamento mais profissional para com os clientes, e esses parecem estar acostumados com um estilo mais pessoal e até mesmo carinhoso. Para o cliente: "Tem a Banca do lado, mas a minha preferência é essa...é uma Banca mais arrumada, mais limpa, mais organizada, isso também atrai, de repente tem uma outra aí com um monte de coisa amontoada, eu nunca passei, nem reparei".

$O$ preço não chega ser um diferencial em termos de vendas, contudo, em certos produtos a Banca 31 tem um valor mais competitivo que o dos supermercados. À guisa de exemplo, um determinado tipo de nozes é vendido em um grande supermercado da região a $\mathrm{R} \$ 36,00$ o quilo, enquanto, na Banca custa $\mathrm{R} \$ 24,00$. Dentro do Mercado, o preço é semelhante entre produtos similares, observamos, inclusive, que se uma Banca baixa o preço a outra acompanha, visto que o cliente argumenta que na concorrência está mais barato.

A revista Veja - unidade Porto Alegre - realiza em três edições anuais uma pesquisa acerca dos estabelecimentos mais citados ligados a área da gastronomia. A eleição é feita com a participação de cinqüenta personalidades, tais como "socielites", "gourmets", jornalistas, que escolhem para cada uma das categorias - restaurante, churrascaria, pizzaria, bar, etc.- um estabelecimento que tenha se destacado. A Banca 31 foi a vencedora, nas duas últimas edições, na categoria "delicatesses", o que lhe rendeu uma boa divulgação e, conseqüentemente, um aumento no número de clientes.

Entretanto, a Banca não possui um espaço que possa abrigar mais funcionários para atender mais pessoas, razão pela qual, às sextas-feiras, no final da tarde, começaram a ocorrer brigas em frente à Banca. Segundo Sérgio, formava-se o "maior barraco", pois dada a aglomeração, uns "furavam a fila" e outros gritavam e discutiam por causa disto. Uma das soluções encontradas foi a instituição, que se deu, a partir de novembro de 2000 , de um sistema de atendimento por fichas numeradas. Porém, criou-se outro problema, os fregueses mais antigos, acostumados com o tratamento personalizado, agora se sentiam reduzidos a um número, além disto, não tinham mais a oportunidade de escolher o atendente a quem estavam sempre habituados a recorrer. Para contornar esta situação, o pessoal da Banca argumenta aos fregueses que esta foi a forma encontrada para democratizar o acesso de todos os clientes aos produtos e ao atendimento, entretanto, ainda trata-se de algo experimental. Uma curiosidade relativa às fichas, é que os funcionários costumam chamá-las como se estivessem cantando um bingo: " ficha 55, dois gringos na coxilha, ou ficha 13, Teresinha Maria Cristina qual a idade da menina".

Trabalham com tele-entrega. As vendas por Internet não fazem parte de seus planos, pelos menos enquanto não conseguirem uma estruturação que lhes permita o atendimento desta fatia de mercado. O problema visualizado, no que tange à estrutura, é que, além do espaço da loja ser pequeno para atender a clientela, também inviabiliza o armazenamento. No Mercado não há condições para grandes estocagens, o que obriga o permissionário a fazê-lo em sua própria casa, tirando a flexibilidade em termos de resposta ao cliente.

O abastecimento da Banca se dá através de fornecedores locais, nacionais e representantes comerciais paulistas para produtos importados. Devido a problemas de armazenagem, já comentados anteriormente, a importação direta é quase inexistente, apesar de ser mais barata. 


\section{O resultado culinário: os diferentes sabores}

O conceito de estratégias (ditas) genéricas advém do fato de que alguns autores (Miles et al., 1978; Mintzberg, 1988; Porter, 1986,1990) acreditam ser possível definir-se uma tipologia de estratégias suficientemente amplas de tal forma que elas sejam aplicáveis a qualquer empresa, em qualquer tipo de indústria e em qualquer estágio de desenvolvimento da indústria. Ou dito de outra forma, poderia ser identificado um número limitado de arquétipos estratégicos que capturariam a essência das diversas posturas competitivas da maioria das empresas.

Porter (1986, 1990) propôs uma tipologia composta por três estratégias genéricas: liderança no custo total, diferenciação e enfoque.

O ponto central da estratégia de liderança no custo total é a empresa fazer com que seu custo total seja menor do que o de seus concorrentes. O custo mais baixo funciona como um mecanismo de defesa da empresa contra a rivalidade de seus concorrentes, especialmente, no tocante à guerra de preços.

A estratégia de diferenciação pressupõe que a empresa ofereça, no âmbito de toda a indústria, um produto 3 que seja cons iderado único pelos clientes, ou seja, cujas características o distingam daqueles oferecidos pela concorrência. A heterogeneidade dos gostos e necessidades dos clientes torna difícil falar-se em um mercado que atinja toda a indústria, quando, na realidade, existem segmentos de mercado. Contudo, o conceito de um produto que atenda a toda a indústria assenta-se no fato de que podem existir características gerais que são valorizadas, em maior ou menor grau, pela maioria dos segmentos de mercado dentro da indústria

A estratégia de enfoque baseia-se no fato de que a empresa será capaz de atender melhor ao seu alvo estratégico do que aqueles concorrentes que buscam atender a toda à indústria (ou a um grande número de segmentos da indústria). $\mathrm{O}$ alvo ou escopo estratégico deve ser suficientemente estreito de forma a permitir que a empresa o atenda mais eficientemente ou mais eficazmente e pode ser definido sob diversas dimensões: tipo de clientes, linha de produtos, variedade do canal de distribuição, área geográfica. $\mathrm{O}$ alvo estreito pode ser atendido através de uma posição de custo mais baixo ou de uma posição de diferenciação, mesmo que a empresa não seja capaz de manter uma destas posições em relação à indústria como um todo.

Analisando sob este enfoque teórico, as bancas de especiarias parecem estar mais voltadas para estratégia de diferenciação, pois procuram colocar o produto como único no mercado. Atendem a um determinado público através de uma linha contendo produtos bastante específicos e de modo geral mais caros que as demais Bancas. Também conseguem distinguir-se através do atendimento ao agregar um saber-fazer ao produto, por exemplo, como prepará-lo, e até saber se ele se adequa ao perfil do cliente, além do atendimento personalizado. Isto fica evidente quando certos clientes relatam que não compram, por exemplo, frios no supermercado perto de casa, optando por se deslocar até o centro da cidade, local onde fica o Mercado. Isto porque, segundo eles, não conseguem consumir outro produto que não seja aquele derecido pelas Bancas de especiarias, conforme os depoimentos que se seguem:

\footnotetext{
3 A rigor, a palavra "produto" deveria ser substituída pela expressão "produto ou serviço". No entanto, de forma a tornar a leitura mais fácil, em todo o texto será utilizada apenas a palavra produto, mesmo quando a situação permita uma inferência também para o ramo de serviços.
} 
"(...) a gente começou a perceber que os frios comprados em supermercados, coisa, não duravam a mesma coisa, e não ficavam frescos ao mesmo tempo que ficava frios comprados aqui, que eram fatiados na hora, qualidade, (...) qualidade".

"(...) pra mim não é a mão, eu tenho que pegar lotação ou táxi pra vir aqui, porque vir de carro é meio complicado pra estacionar, embora aqui tenha estacionamento, mais (ah, ah). Agora no caso eu tô passando pelo centro tá , mas de uma forma geral eu saio de casa, moro no bairro Mont'Serrat e venho aqui só pra especificamente pra isso".

Diante do quadro construído por Conant et al. (1990) procuramos analisar as estratégias desenvolvidas nas Bancas de especiarias do Mercado Público.

No aspecto domínio de produtos e mercados observamos que há uma segmentação quanto a classe social: há produtos mais voltados para a classe A e outros para a classe $\mathrm{B}$ e $\mathrm{C}$, ajustados conforme a evolução econômica. Procuram detectar as necessidades do cliente, que muitas vezes, lhes fornecem dicas de novos produtos oferecidos em outros lugares que passam a ser comprados para atender a freguesia. Contudo, mantêm uma linha de produtos estável e bastante focado.

Quanto à postura de sucesso notamos que há investidas oportunas como, por exemplo, quando há grandes eventos envolvendo o Mercado Público, buscam estar sempre vinculados e oferecendo produtos de suas Bancas. Também se adaptam conforme as situações se colocam, como a Banca 31 que precisou implantar um sistema de fichas de atendimento pois não conseguia em certos horários atender os fregueses de forma ordenada. Já a Banca 43 procura, através de um atendimento personalizado, atender as necessidade de seus clientes, que são levados para dentro da mesma, sem, entretanto, procurar antecipar-se e criar novos "modus operandi". No dizer de um dos permissionários da Banca 43: '(...) nós não gostamos do freguês tá longe de nós, ter esse freguês junto, perto para gente conversar, para bater um papo. (...) perguntando o que quer levar o que não quer. Esse é o nosso lance".

As Bancas de especiarias estão orientadas para a concorrência, isto porque ficam monitorando a mesma, principalmente, no aspecto preço. Notamos que quando a concorrente altera o preço o reflexo se dá em ambas, ou seja, na Banca 31 e na Banca 43, cabendo ressaltar que as duas são fortes concorrentes na medida em que possuem um perfil bastante parecido em termos de produtos e serviços. Um determinado produto que aparece na concorrência, em seguida é adquirido pelas duas Bancas.

Quanto ao aspecto crescimento, notamos a cautela, não há pressa, preferem não arriscar, dizem que a margem de lucro nos últimos anos diminuiu razoavelmente e qualquer investimento precisa ser bem calculado para não gerar prejuízos. Os permissionários da Banca 43, neste aspecto, preferem adquirir mercadorias em quantidades menores que a demanda, e demorar um ou dois dias para atender ao cliente, do que a oferta suplantar as necessidades dos clientes e os permissionário verem-se obrigados a dividir a sobra com os funcionários para não jogar fora, de qualquer maneira é dinheiro perdido, na visão dos donos da Banca.

Procuram associar qualquer investimento, principalmente o tecnológico, com a eficiência de custos. Observamos isto quando as Bancas de especiarias adquirem novos equipamentos para manusear os frios, geralmente, levam em conta a possibilidade de menor perda (ou maior rentabilidade do produto) e maior satisfação do cliente, alavancando, assim, as vendas. À guisa de exemplo: há clientes que gostam de um determinado embutido cortado com uma espessura 
ultrafina, e para isto há necessidade de equipamentos que tenham esta peculiar graduação, todavia, na hora de comprar tal maquinário, é analisado o desempenho do produto em termos de agilidade (manuseio) e desperdício (produto).

Também notamos que procuram adquirir uma tecnologia focada no aspecto central do negócio, desta forma conseguem atentar para os aspectos tecnológicos, mas mediante baixos investimentos. Diante disto, muitas vezes, procuram improvisar soluções, pois não possuem um programa de manutenção e nem pessoal técnico habilitado.

Cabe salientar que ainda estão muito arraigados no atendimento pessoal como arma para a sobrevivência do negócio, a questão de investimento em equipamentos parece que tira o ar de tradição e começa a inserir a modernidade, o que de certa forma, para eles, descaracteriza o negócio e a própria relação entre o mercadeiro e cliente. A degustação e a preparação manual parece fazer parte do ritual de compra e venda nestas Bancas.

Apesar de serem negócios de pequeno porte possuem uma certa organização em termos de planejamento de compras, controle financeiro e vendas. As áreas de finanças e produção estão bem alinhadas para não haver nenhum desperdício. Diante disto o planejamento é de dentro para fora e dominado por controle, principalmente, o financeiro. A estrutura é funcional, cada pessoa exerce uma determinada tarefa sendo que a autoridade é reconhecida/centrada por um grupo pequeno dentre os que atuam na organização.

As Bancas estão predominantemente voltadas para as características da tipologia defensiva quanto ao seu comportamento estratégico, tendo nuances de características analíticas e reativas.

\section{A surpresa gastronômica}

Quando decidimos estudar as bancas de especiarias imaginamos encontrar métodos mais informais na formulação de estratégias, porém, nos surpreendemos. Os mercadeiros são organizados, além disto, possuem um "feeling" interessante para gerenciar. Procuram equilibrar tradição e modernidade, pois apesar de estarem embuídos por ritos, mitos e costumes, estão atentos para as oportunidades que os meios modernos oferecem, como é o caso do uso da Internet para vendas. Ficou igualmente claro, que a compra e venda dos produtos, no Mercado Público, remete os atores envolvidos a um universo simbólico onde a razão prática é humanizada pela afetividade, pelo fato de ultrapassarem a relação entre indivíduos pela relação entre pessoas (DaMatta, 1987), externalizada em atos tais como a identificação das preferências de cada um dos consumidores, a escolha de um atendente em especial, a troca de receitas, o conhecimento de aspectos familiares. A dádiva (Mauss, 1974) nas sociedades complexas hodiernas também se faz presente e não se restringe a bens materiais, mas sim a aspectos imateriais, como o carinho de um atendimento personalizado.

\section{Referências Bibliográficas}

CONANT, J.S., MOKWA, M.P. e VARADARAJAN, P.R. Strategy types, distinctive marketing competencies and organizational performance: a multiple measures- 
based study. Strategy Management Journal, v. 11, p. 365-383, 1990.

DAMATTA, R.. A Casa e a Rua: Espaço, Cidadania, Mulher e Morte no Brasil, Rio de Janeiro, Guanabara, 1987.

GIMENEZ, F.P., PELISSON, C., KRÜGER, E.G.S. e HAYASHI, P. Estratégia competitiva de pequenas empresas varejistas. In: ANGELO, C. e SILVEIRA, J.A.(Org.). Varejo Competitivo, v. 3, São Paulo, Atlas, 1999.

MALINOWSKI, B. Argonautas do Pacífico Ocidental. São Paulo, Abril Cultural, 1978.

MAUSS, M. Sociologia e Antropologia. São Paulo, EPU, v.II, 1974.

MILES, R. E., SNOW, C. C., MEYER, A. D. \& COLEMAN, H.J., Organizational Strategy, Structure, and Process. Academy of Manageme nt Review, v.3, n.3 p.546-562, July 1978.

MINTZBERG, H.; AHLSTRAND, B. E LAMPEL, J. Safári de Estratégia. Porto Alegre, Bookman, 2000.

MOTTA, P.R. Gestão Contemporânea: a ciência e a arte de ser dirigente. Rio de Janeiro, Record, 1991.

PORTER, M. Vantagem Competitiva: Criando e Sustentando um Desempenho Superior. Rio de Janeiro, Campus, 1986.

, Estratégia Competitiva: Técnicas para Análise de Indústrias e da Concorrência. Rio de Janeiro, Campus, 1986.

, The Competitive Advantage of Nations. Harvard Business Review, Apr, 1990.

VIET J., Métodos Estruturalistas nas Ciências Sociais. Rio de Janeiro, Tempo Brasileiro, 1967. 